\title{
A Web based Information Security Risks Assessment Model
}

\author{
B. K. Alese, O. Oyebade, O. Iyare, Osuolale A. Festus, A. F. Thompson \\ Computer Science Department \\ Federal University of Technology \\ Akure, Ondo State, Nigeria
}

\begin{abstract}
A risk is the possibility that an undesirable event could happen. Different methodologies have been proposed to assess and manage IT risks each of which is divided into processes and steps. Two specific methods of interest in this work are: "Risk Matrices" and "Risk Registers". A generic Risk Register application module and an updatable Risk Matrix module were designed. This work studies risk management techniques and employs a custom model for the automated assessment of IS risks. This model was implemented in phases corresponding to its aspects. The "Assessment methods" of interest to this work are Risk Registers, Risk Matrices and the Scenario Geek". What-if analysis is a data-intensive simulation whose goal is to inspect the behavior of a complex system under some given hypotheses called scenarios. What-ifs are used to generate qualitative descriptions of potential problems in the form of questions and responses lists of recommendations for preventing problems. The Risk Assessor was developed using Microsoft's Visual Basic.Net with Active Server Pages (ASP.Net) Technologies on .Net Framework 4.0. The solution propounded in this work is a good risk management application that provides upward assurance from information technology security issues, business activities and administrative functions and ultimately to anyone that chooses to adopt it.
\end{abstract}

\section{Introduction}

A risk is the possibility that an undesirable event (called the risk event) could happen. Risks involve both uncertainty (as events that are guaranteed to happen are not risks) and loss (events that do not negatively affect the project are not risks). Risks can come from uncertainty in information security, financial markets events, project failures (at any phase in design, development, production, or sustainment life-cycles), legal liabilities, credit risk, accidents, natural causes and disasters as well as deliberate attack from an adversary, or events of uncertain or unpredictable root-cause. The strategies to manage risk typically include transferring the risk to another party, avoiding the risk, reducing the negative effect or probability of the risk, or even accepting some or all of the potential or actual consequences of a particular risk. Certain aspects of many of the risk management standards have come under criticism for having no measurable improvement on risk, whether the confidence in estimates and decisions seem to increase [1].

Risk management was defined by [1] as the identification, assessment, and prioritization of risks (defined in ISO 31000 as the effect of uncertainty on objectives, whether positive or negative) followed by coordinated and economical application of resources to minimize, monitor, and control the probability and/or impact of unfortunate events or to maximize the realization of opportunities. Several risk management standards have been developed including the Project Management Institute, the National Institute of Standards and Technology, actuarial societies, and ISO standards [2], [3]. Methods, definitions and goals vary widely according to whether the risk management method is in the context of project management, security, engineering, industrial processes, financial portfolios, actuarial assessments, or public health and safety.

Different methodologies have been proposed to manage IT risks, each of them divided into processes and steps [4]. According to Risk IT, it encompasses not just only the negative impact of operations and service delivery which can bring destruction or reduction of the value of the organization, but also the benefit/value enabling risk associated to missing opportunities to use technology to enable or enhance business or the IT project management for aspects like overspending or late delivery with adverse business impact. Since risk is strictly tied to uncertainty, Decision theory should be applied to manage risk as a science which is rationally making choices under uncertainty.

The process of risk management encompasses, majorly, three activities, which are: Establishing the context (it involves identification of risk in a selected domain of interest, planning the remainder of the process, mapping out the social scope of risk 
management, the identity and objectives of stakeholders \& the basis upon which risks will be evaluated, constraints, defining a framework for the activity and an agenda for identification, developing an analysis of risks involved in the process, mitigation or solution of risks using available technological, human and organizational resources), Identification of the Risks (After establishing the context, the next step in the process of managing risk is to identify potential risks. Risks are about events that, when triggered, cause problems. Hence, risk identification can start with the source of problems, or with the problem itself.), and Assessment (Once risks have been identified, they must then be assessed as to their potential severity of impact and to the probability of occurrence).

\section{Related Works}

The IT risk management is the application of risk management to Information technology context in order to manage IT risk, that is the business risk associated with the use, ownership, operation, involvement, influence and adoption of IT within an enterprise IT risk management can be considered a component of a wider Enterprise risk management system [5].

In risk management, possible risks must be identified. Different methodologies have been proposed to manage IT risks, each of them divided into processes and steps [4]. After the risks have been identified, they must be assessed to determine their potential severity of impact (generally a negative impact, such as damage or loss) and the probability of occurrence.

The fundamental difficulty in risk assessment is determining the rate of occurrence since statistical information is not available on all kinds of past incidents. Furthermore, evaluating the severity of the consequences (impact) is often quite difficult for intangible assets.

According to Kohout [6], risk management process is a systematic application of management policies, procedures and practices to the activities of communicating, consulting, establishing the context, and identifying, analyzing, evaluating, treating, monitoring and reviewing risk. The risk register should support and store generic data from most phases, including monitoring and review. Risk register (sometimes referred to as risk $\log$ ) is a key part of documenting any risk analysis and one of the most important supporting tools of risk management, enabling storage and communication of information in a relevant, consistent and concise manner.

In Gordon et al. [7], assessment of IT security risks was carried out using hybrid expert system since the uncertainty and unexpectedness of security risk makes it challenging to assess and monitor. The authors proposed the use of fuzzy logic as well as the theory of certainty factor to carry out risk assessment. In their model, they considered risk assessment in the context of a fuzzy logic system with the input unit, inference engine and output unit as the basic blocks.

\section{Model Design}

The architecture encompasses three major groups of components, namely: Server-Side Components, the Cloud and the Client-Side Component. It is a formal description and representation of the system and it provides a plan from which the risk assessment can be executed and implemented with infrastructure (hardware and networking).

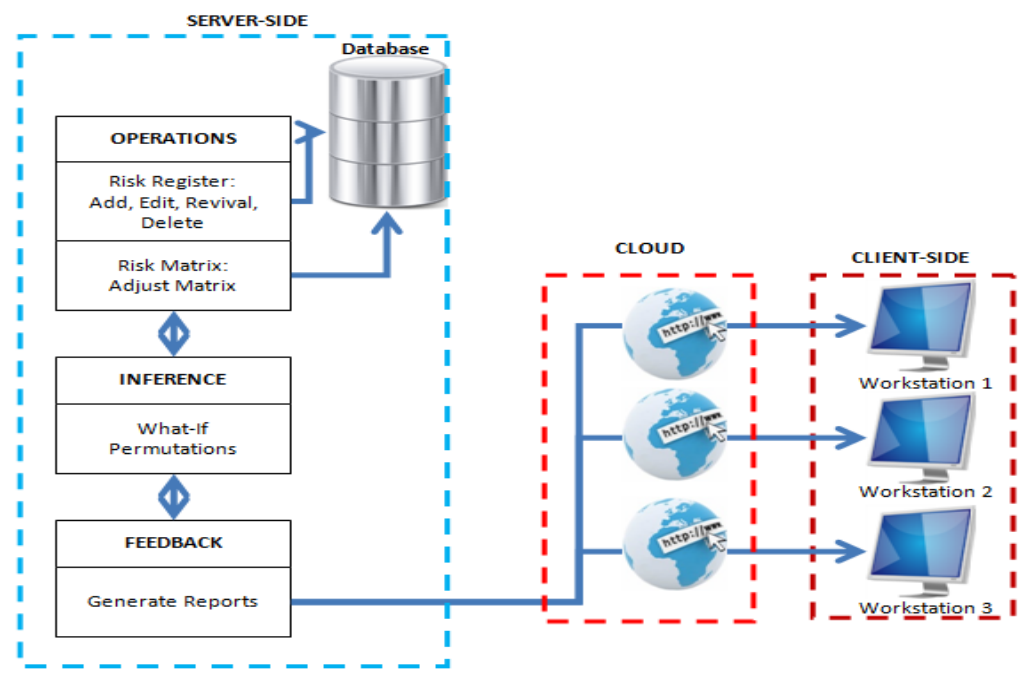

Figure 1. System Architecture 
The software sits on a remote server as shown in figure 1 where all server-side operations (ranging from database access to business logic) are carried out. The end users will place queries from the ClientSide via the web and get feedbacks in the form of reports from their respective terminals or workstations.

\subsection{Database Object Models}

The Figure 2 presents the risk matrix and register object class diagram. It adopts the concept of ObjectOriented Modeling in the design of the backend of the new system.

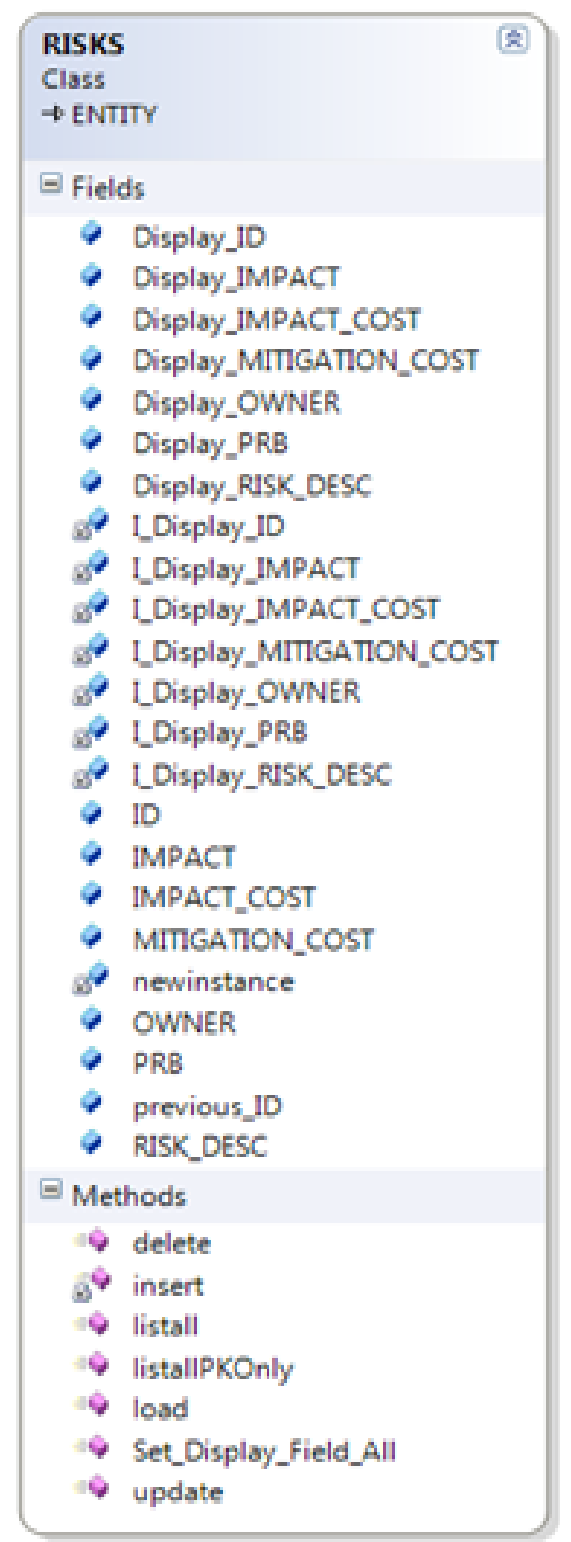

\begin{tabular}{|c|c|}
\hline \multicolumn{2}{|c|}{$\begin{array}{l}\text { RISK_MATRIX } \\
\text { Class } \\
\Rightarrow \text { ENTITY }\end{array}$} \\
\hline \multicolumn{2}{|c|}{$\square$ Fields } \\
\hline$\bullet$ & AMBER_LOWER \\
\hline$\bullet$ & AMBER_UPPER \\
\hline 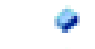 & Display_AMBER_LOWER \\
\hline$\bullet$ & Display_AMBER_UPPER \\
\hline$\bullet$ & Display_GREEN_LOWER \\
\hline 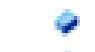 & Display_GREEN_UPPER \\
\hline$\bullet$ & Display_ID \\
\hline$\bullet$ & Display_RED_LOWER \\
\hline$\bullet$ & Display_RED_UPPER \\
\hline$\bullet$ & GREEN_LOWER \\
\hline 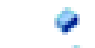 & GREEN_UPPER \\
\hline$s$ & I_Display_AMBER_LOWER \\
\hline s? & I_Display_AMBER_UPPER \\
\hline s? & L_Display_GREEN_LOWER \\
\hline s? & I_Display_GREEN_UPPER \\
\hline se & L_Display_to \\
\hline s? & I_Display_RED_LOWER \\
\hline 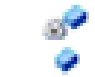 & $\begin{array}{l}\text { I_Display_RED_UPPER } \\
\text { ID }\end{array}$ \\
\hline$\sigma^{\circ}$ & newinstance \\
\hline$\bullet$ & previous_ID \\
\hline 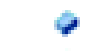 & RED_LOWER \\
\hline 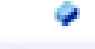 & RED_UPPER \\
\hline \multicolumn{2}{|c|}{ Methods } \\
\hline$\theta$ & delete \\
\hline $6^{\circ}$ & insert \\
\hline 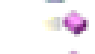 & listall \\
\hline 4 & listallPKOnly \\
\hline 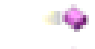 & load \\
\hline 4 & Set_Display_Field_All \\
\hline 4 & update \\
\hline
\end{tabular}

Figure 2. Risk Matrix and Register Object Class Diagrams

Object Database Management Systems (ODBMS) offers features such as Persistence, Object Identity, Encapsulation, Computational completeness, Complex Objects: Extensibility, Types and Classes, Inheritance, Overriding and overloading, Secondary storage management, Transactions and Concurrency, and Recovery which is all crucial and adopted in the implementation of this new system.
Figure 2 shows two classes, their respective attributes and methods.

\subsection{What-If Model}

What-if analysis is a data-intensive simulation; the aim is to inspect the behavior of a complex system under some given hypotheses called 
scenarios. what-if analysis measures how changes in a set of independent variables impact a set of dependent variables with reference to a given simulation model. Simulation model supports one or more scenarios, each describing one or more alternative ways to construct a prediction of interest for the user.

\subsection{Multiple Scenario Diagram}

The scenarios considered in this work are described with a structure diagram consisting of multiple branches, leading to either one of two categories of reports.

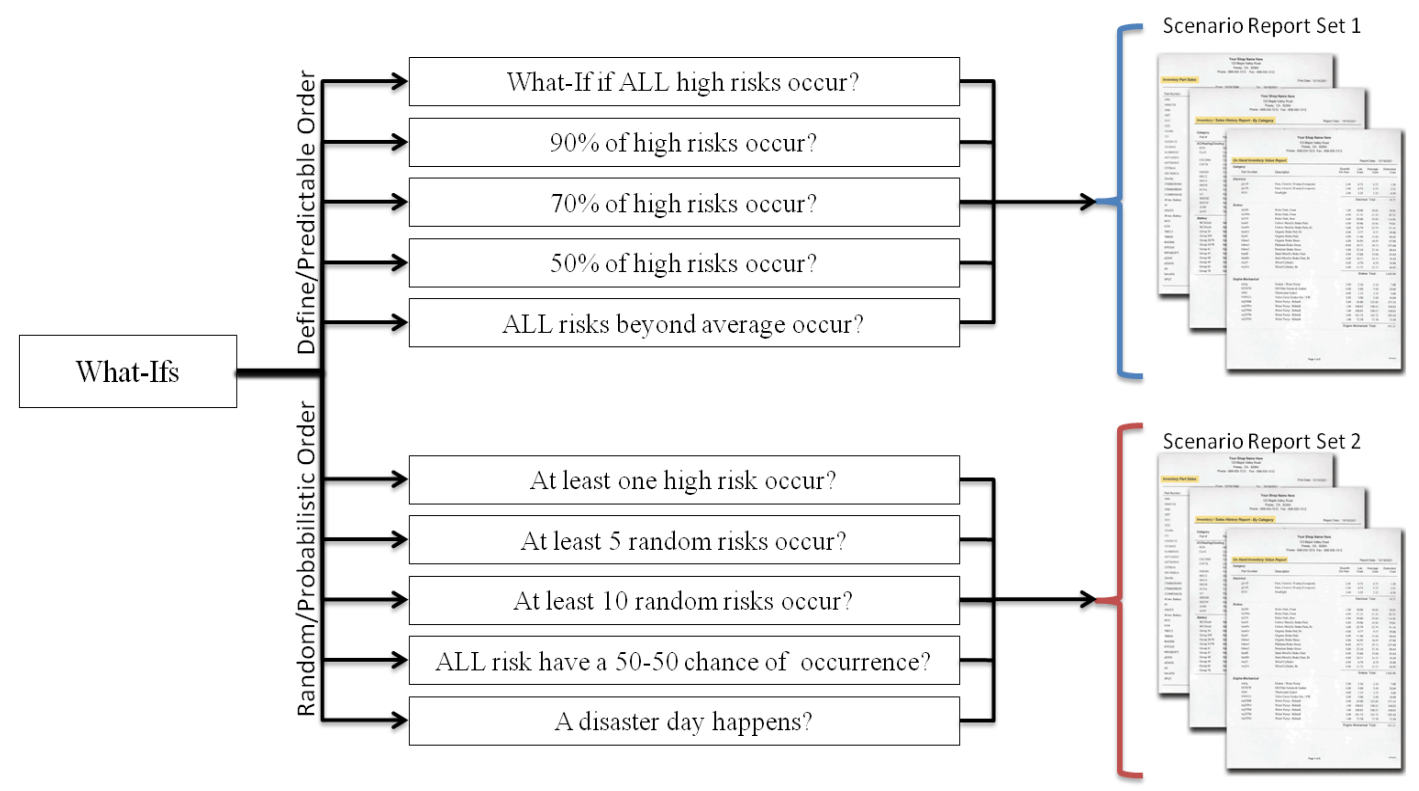

Figure 3. Multiple Scenario Diagram

\subsection{Scenario Geek Model}

Let the impact of risk recurrence, $\mathrm{I}_{\mathrm{i}}^{\mathrm{E}}$ (instance of risk event ) where $\mathrm{I}=0,1,2,3$. $n$ be defined such that

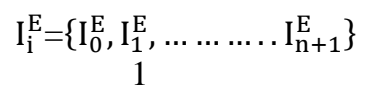

where $\mathrm{I}_{\mathrm{i}}^{\mathrm{E}} \subseteq \mathrm{R}^{+}$bound at $[1,5]$ that is $\left\{x \in \mathrm{I}^{E}: 1 \leq\right.$ $x \geq 5\}$. Suffixes to show that the sum of impact $\sum_{i=0}^{n} \mathrm{I}_{i}^{\mathrm{E}}$ for $(\mathrm{n}+1)$ instance of impact of risk event $\mathrm{I}^{\mathrm{E}}$

$$
\sum_{i=0}^{n} \mathrm{I}_{i}^{\mathrm{E}}=\left\{\mathrm{I}_{0}^{\mathrm{E}}+\mathrm{I}_{1}^{\mathrm{E}}+\mathrm{I}_{2}^{\mathrm{E}} \cdots \cdots \cdot \mathrm{I}_{n}^{\mathrm{E}}\right\} 2
$$

Let $\overline{\mathrm{I}_{l}^{\mathrm{E}}}$ be the calculated average value of impact of risk event $\mathrm{I}_{i}^{\mathrm{E}}$ for $\mathrm{i}=0,1,2, \ldots \ldots \ldots$ therefore $\overline{\mathrm{I}_{l}^{\mathrm{E}}}$ can thus be defined for $(n+1)$ instances as;

$\overline{\mathrm{I}_{l}^{\mathrm{E}}}=\frac{\sum_{i=0}^{n} \mathrm{I}_{i}^{\mathrm{E}}}{(n+1)}$
Thus calculated impacts above or below average can be deduced with the knowledge of $\overline{\mathrm{I}_{l}^{\mathrm{E}}}$

Suppose there exist a set of possible information technology risks ${ }_{k}^{\mathrm{j}} R_{f}$ where $\mathrm{I}=0,1,2 . \ldots \ldots \mathrm{m}$;

$\mathrm{j}, \mathrm{k} \in \mathbb{N}$ and $0 \leq k \geq j$ is defined as

$$
{ }_{k}^{j} R_{f i}=\underset{4}{\left\{r_{0}, r_{1}, r_{2}, \ldots \ldots . . r_{m}\right\}}
$$

For $(m+1)$ possible instances of such risks where $\mathrm{j}=$ risk sample space (interval of occurrence) and $\mathrm{k}=$ frequency

of occurrence. Therefore it suffices to show that the probability of risk occurrence is:

$P\left({ }_{k}^{j} R_{f i}\right)=\left\{P\left(r_{0}\right), P\left(r_{1}\right), P\left(r_{2}\right), \ldots P\left(r_{m}\right)\right\}$

Where $P\left({ }_{k}^{j} R_{f i}\right) \subseteq R^{+}$bound at $[1,5]$ that is

$$
\left\{y \in p\left({ }_{k}^{j} R_{f}\right): 1 \leq y \geq 5\right\}
$$


Hence, the composite risk index $C_{i}$ a risk level evaluator is a product of the impact of the risk event $I_{i}^{E}$ and the probability of the risk occurrence $P\left({ }_{k}^{j} R_{f i}\right)$.

Therefore taking a product of the equation 1 and 6 for $\forall \epsilon C_{i}$

$C_{i}=\left\{\left(\mathrm{I}_{0}^{E} * P\left(r_{0}\right)\right),\left(\mathrm{I}_{1}^{E} * P\left(r_{1}\right)\right), \ldots \ldots \ldots\left(\mathrm{I}_{n}^{E} *\right.\right.$

$\left.\left.P\left(r_{m}\right)\right)\right\} \quad 7$

Where $\mathrm{C}=\left\{\begin{array}{lll}\mathcal{Z} & \text { if } & \mathcal{Q}<Z \geq 25 \\ \mathcal{Y} & \text { if } & \mathcal{P}<Y \leq Q \\ \mathcal{X} & \text { if } & 1 \leq x \leq \mathcal{P}\end{array}\right.$

8

Where $\mathcal{X}, \mathcal{Y}, \mathcal{Z}, \mathcal{P}, \mathcal{Q} \in \mathcal{Z}^{+}$bounded by $[1,25]$ are $\mathcal{P}$ and $\mathcal{Z}$ values a reasonable trivial value of choice by company management. Hence $C_{i}$ for $(\mathrm{n}+1)$ possible instance can then be defined as

$C_{i}=\prod_{i=0}^{n} \underset{9}{\mathrm{I}_{I}^{\mathrm{E}}} P\left(r_{i}\right)$

It suffices to show that the average CRI, $\bar{C}_{l}$ can thus be defined as

$C_{i}=\frac{\sum_{i=0}^{n} \Pi \mathrm{I}_{i}^{\mathrm{E}} P\left(r_{i}\right)}{(n+1)}$

10

\section{A. Scenario Geek Algorithm}

In this section, we present an expression of the scenarios in algorithms.

\section{Scenario 1: All Risk Occurs}

The method in algorithm 1 computes the sum of impacts of all risks across the database table with the assumption that all risks has happened.

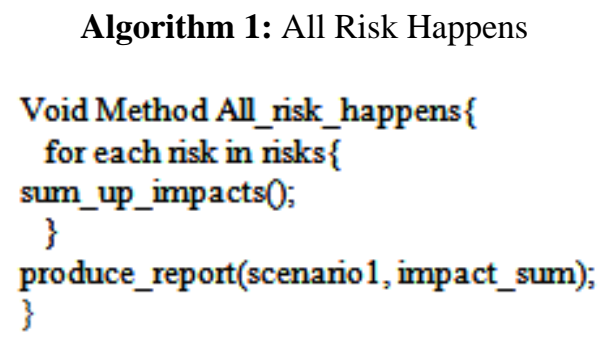

\section{Scenario 2: A Percentage of All Risks Occurs}

Algorithm 2 addresses all percentage-centered risk computations. It takes as a parameter, the percentage of the risks to be postulated as occurred and sums up all impacts to produce a report of the simulated damages.

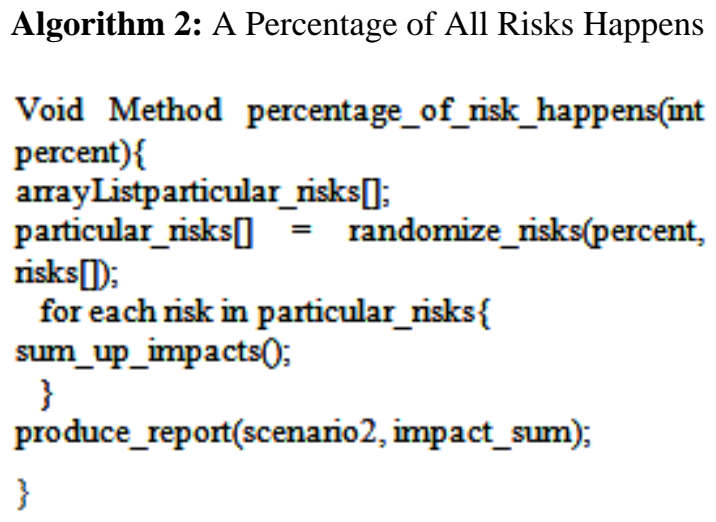

\section{Scenario 3: All Risks beyond Average Occurs}

In Algorithm 3, we continue by estimating the potential impact if all risks beyond the risk matrix's average benchmark happens. The algorithm takes the lower bound of the average range (Amber rating), compares it against the computed CRI (composite risk index) and sums up the impact of all risks found in the range, fulfilling the condition.

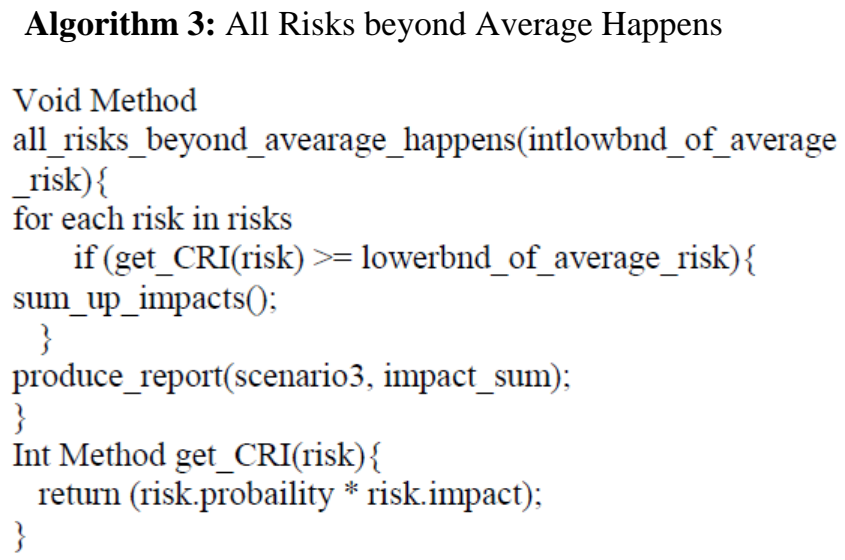

\section{Scenario 4: At Least One High Risk Happens}

In this scenario we used random numbers. A risk is selected without bias and assumed to have happened and the corresponding impact is passed to the report production module. This is illustrated with algorithm 4. 


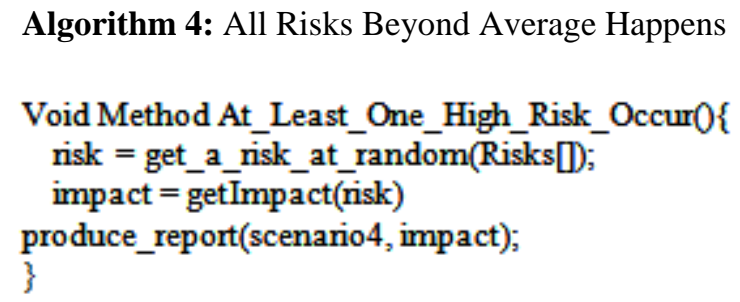

\section{Scenario 5: At Least N-High Risk Happens}

This scenario is a generalization of Scenario 4. In scenario five, we postulate for $\mathrm{N}$-occurrences of randomly selected risk events and generate a report on same.

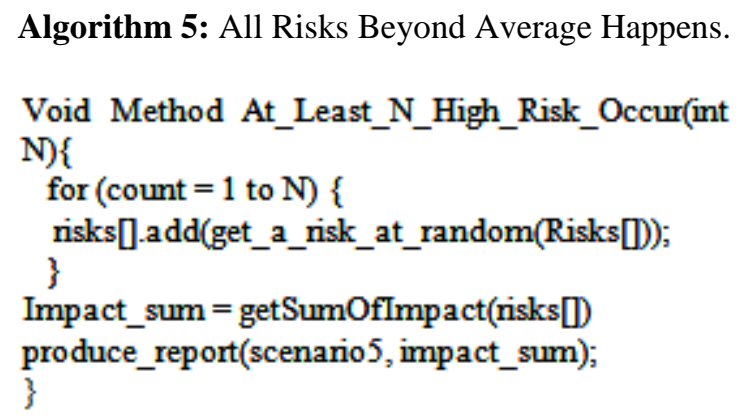

\section{Implementation}

The Risk Assessor was developed using Microsoft's Visual Basic.Net with Active Server Pages (ASP.Net) Technologies on .Net Framework 4.0. SQL Server was used in storing the data being manipulated by the new system. The quantitative risk assessments was carried out using pseudorandom numbers to auto-assume weights for risks and also generate different scenario permutations of the risk occurrence.

The multiple scenarios resulting from different situations in risk occurrence produces a stack of permutations, given by the expression: $2^{n}$; where $n$ is the number of risk events.

In real life situations, the magnitude of risk events faced by organizations suggests that the resultant scenarios grow at an exponential rate. Table 1 shows the mapping of Number of risk event to the distinct scenarios obtainable.

Table 1. Mapping from Risk Count to Scenarios

\begin{tabular}{|c|c|c|}
\hline $\begin{array}{c}\text { Number } \\
\text { of } \\
\text { Risks }\end{array}$ & $\begin{array}{c}\text { Distinct } \\
\text { Scenarios } \\
\text { (Permutations) }\end{array}$ & \multicolumn{1}{|c|}{ Comment } \\
\hline 1 & 2 & $\begin{array}{l}\text { It is either the risk } \\
\text { happens or it does } \\
\text { not (this is a two- } \\
\text { scenario) }\end{array}$ \\
\hline
\end{tabular}

\begin{tabular}{|l|c|l|}
\hline 2 & 4 & \\
\hline 3 & 8 & \\
\hline 4 & 16 & \\
\hline 5 & 32 & \\
\hline 6 & 64 & \\
\hline 7 & 128 & \\
\hline
\end{tabular}

The tolerance level of the Organization is a monetary value specified in Naira which represents a benchmark or threshold of the risk the firm is willing to take. The following are the simulation results obtained.

Simulation 1:

What-If Scenario: 10 out of 100 risks occur.

Risk Sample Space: 100 Risks

Tolerance Level: 750,000.00 (Threshold of Risk Acceptance).

Table 2. Result from Simulation 1

\begin{tabular}{|c|c|c|}
\hline SN & Risk ID & $\begin{array}{c}\text { Quantitative } \\
\text { Impact }\end{array}$ \\
\hline 1 & $\mathrm{R}-7$ & 45,218.63 \\
\hline 2 & R-64 & 233,778.63 \\
\hline 3 & $\mathrm{R}-49$ & N 33,006.93 \\
\hline 4 & $\mathrm{R}-28$ & 45,598.63 \\
\hline 5 & R-39 & N $157,469.85$ \\
\hline 6 & $\mathrm{R}-82$ & ₹ $72,769.03$ \\
\hline 7 & R-94 & $76,467.31$ \\
\hline 8 & $\mathrm{R}-47$ & 45,469.03 \\
\hline 9 & $\mathrm{R}-83$ & * $6,969.03$ \\
\hline 10 & $\mathrm{R}-32$ & ₹ $23,469.57$ \\
\hline & Sum of Impact & 740,216.67 \\
\hline & ACCEPT RISK? & YES \\
\hline
\end{tabular}

\section{Simulation 2:}

What-If Scenario: 10 out of 100 risks occur. 
Risk Sample Space: 100 Risks

Tolerance Level: 700,000.00

Table 3. Result from Simulation 2

\begin{tabular}{|c|c|c|}
\hline SN & Risk ID & $\begin{array}{c}\text { Quantitative } \\
\text { Impact }\end{array}$ \\
\hline 1 & $\mathrm{R}-76$ & $90,663.41$ \\
\hline 2 & $\mathrm{R}-60$ & $46,055.40$ \\
\hline 3 & $\mathrm{R}-34$ & $21,577.73$ \\
\hline 4 & $\mathrm{R}-17$ & $623,240.18$ \\
\hline 5 & $\mathrm{R}-65$ & $76,334.29$ \\
\hline 6 & $\mathrm{R}-40$ & $32,684.46$ \\
\hline 7 & $\mathrm{R}-51$ & $37,500.51$ \\
\hline 8 & $\mathrm{R}-74$ & $21,577.73$ \\
\hline 9 & $\mathrm{R}-30$ & $71,870.51$ \\
\hline \multirow[t]{3}{*}{10} & $\mathrm{R}-15$ & * $320,234.29$ \\
\hline & Sum of Impact & 1,341,738.54 \\
\hline & ACCEPT RISK? & NO \\
\hline
\end{tabular}

A larger scale of simulation is carried out in Simulation 3 and result of same is displayed in Table 5. In this case, 10 iterations of 20 different permutations of risks events are presented with the quantitative sum of impacts and the automated "recommendation" provided by the simulator is appended on the last column of the results.

\subsection{User Management}

Application users can create user accounts within the new system (as shown in Figure 4) while their tokens are kept for user verification on system log on.

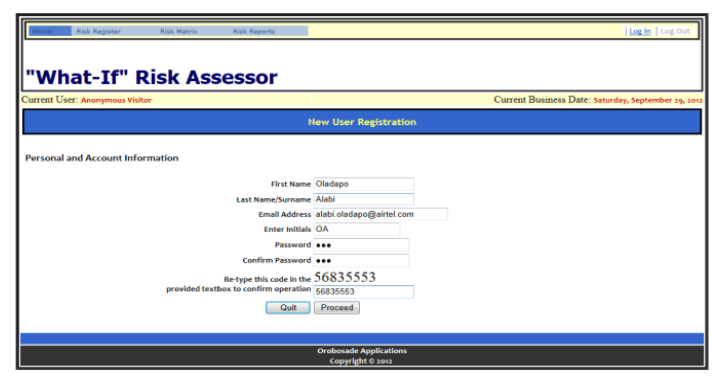

Figure 4. Creating a New User
The menu navigation bar provides hyper-linked buttons directing to several different pages of the application, while the login status, located at the top right corner, shows if a user is logged in or not. If a user is logged in, the log-in button is grayed out (not made available) and if otherwise, its other toggle button (logout) is grayed instead. This is illustrated in Figure 5.

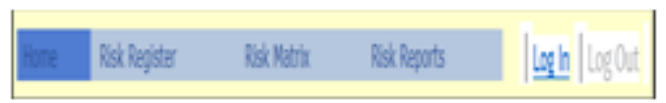

Figure 5. Risk Assessor Menu

For a registered user that clicks on "Log in", a pop up window (powered with AJAX control toolkit) comes up as shown in Figure 6.

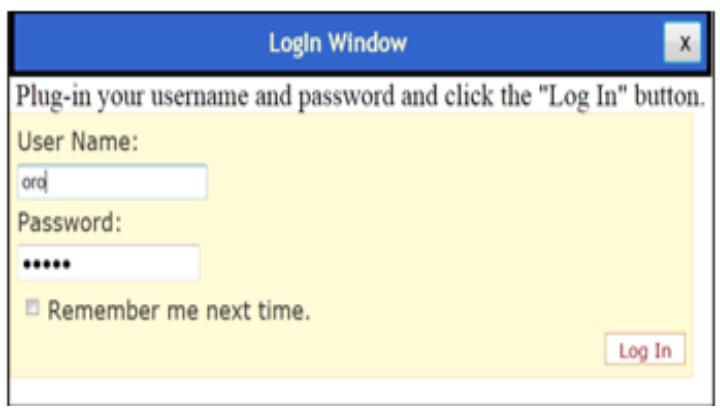

Figure 6. Log-in Pop-up Window

Provided that given tokens are correct and authenticated by the system, access will be granted to the user and the user's name will appear in the navigation bar as shown in Figure 7.

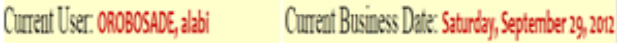

Figure 7. User's Profile Display

\subsection{Electronic Risk Register}

Following a successful login, the application menu items are made available. A major functionality of the new system is the Electronic Risk Register which is represented by a link on the menu bar. This link navigates the user to the Risk Register web page that is shown in Figure 8.

In figure 8, a dataset is displayed with nine (9) fields of different data types, some of which are lifted from the database and others computed on the server-side; showing a simulation of a real life risk register.

The electronic risk register presents the description of all risks, the respective risk owners, probability of occurrence (in a range of 1-5, 5 for highest), impact of risk, priority of risk (a resultant of composite risk index), cost of mitigation and the cost of loss if risk occurs. 


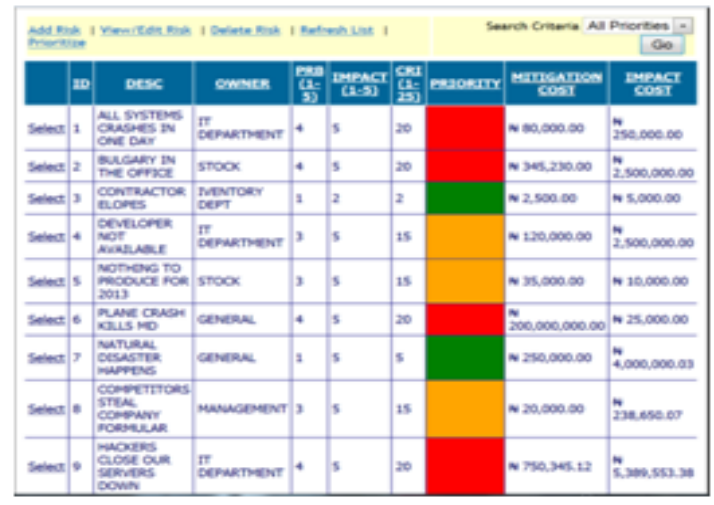

Figure 8. New Electronic Risk Register

This risk database can be appended by clicking the "Add Risk" link button above the grid. Figure 9 shows the pop-up window for adding a new risk event to the register.

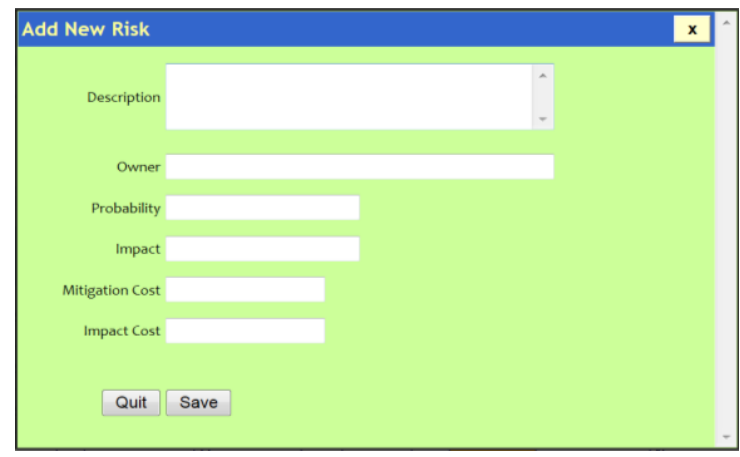

Figure 9. Adding New Risk to Register

\subsection{Automated Risk Matrix}

The Risk Matrix sets the tune for the Register's Priority field. A CRI is computed as a product of probability and impact and the result is grouped into either one of three categories (low, average, high), depending on the predefined matrix. Figure 10 shows the ranges' menu and Figure 11 the update screen for the risk matrix respectively.

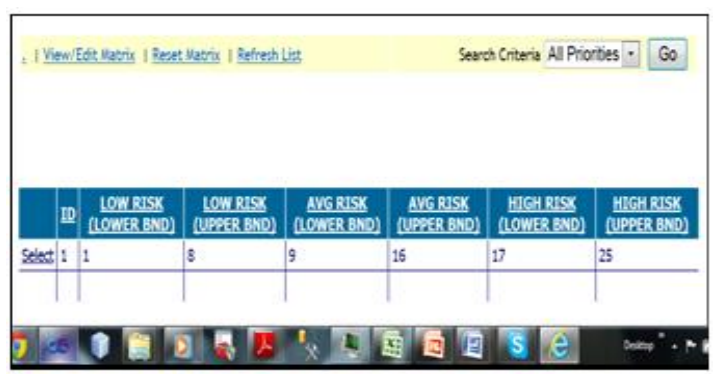

Figure 10. Risk Matrix Grid

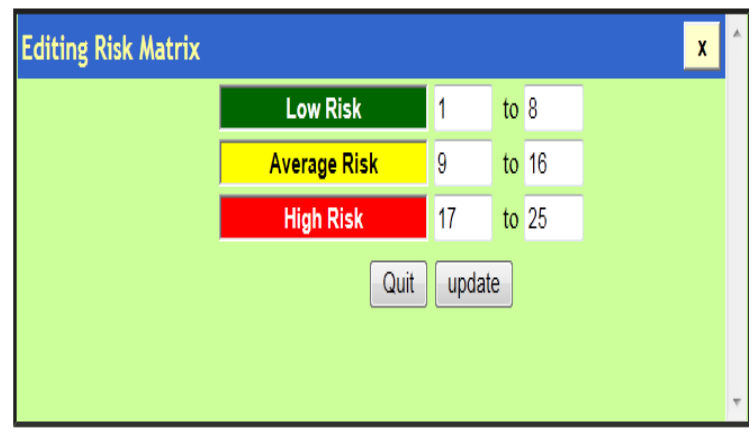

Figure 11. Updating Matrix

\subsection{Evaluation Reports}

After housing the risk register and matrix in a relational database, the desire of any organization will be to evaluate a current position of risk from time to time. This can be done by simply navigating to the report page of the new system. The reports generated by this system are results from real-time computations and made available in a variety of file formats (including Portable Document Format, Excel, Rich Text and Word) as shown in Figure 12.

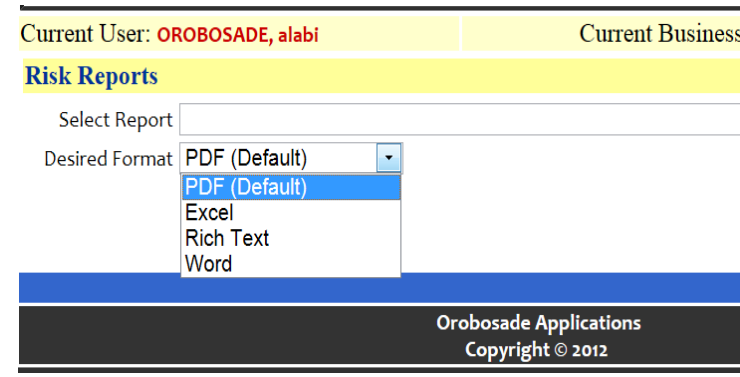

Figure 12. Mutiple File Format

\section{Conclusion}

The importance of having a risk assessment model for information technology risks in an organization cannot be overemphasized. The assessment procedure helps us keep track of the basic sources that can hamper the operations of the organization. The risk assessment procedure presented in this work is very simple and systematic. However, the techniques described are well-known and established but the implementation presented here is unique.

Similar research carried out in the past revealed that using technology in Risk Management provides assurance that: objectives are likely to be achieved; damaging things are less likely to happen; beneficial things are likely to be achieved. The aim of risk management is not to eliminate risk, rather to manage the risks involved in any activity to maximize opportunities and minimize adverse effects. Another notable discovery of this work is that risk management is not the management of 
insurable risks. Insurance is an important way of transferring risk but most risks will be managed by other means.

The solution propounded in this work is a good risk management application that provides upward assurance from information technology security issues, business activities and administrative functions and ultimately to anyone that chooses to adopt it.

\section{References}

[1] Hubbard, D., (2009). The Failure of Risk Management: Why It's Broken and How to Fix It. John Wiley and Sons. p. 46.

[2] ISO-IEC, (2009). ISO-IEC Guide 73:2009 Risk management - Vocabulay, International Organization for Standardization.http://www.iso.org/iso/iso_catalogue/ catalogue_ics/catalogue_deta-ail_ics.htm?csnumber= 44651, (Access date: 23 April, 2015).

[3] ISO-DIS, (2009). Risk management - Principles and guidelines on implementation, http://www.iso.org/iso/ iso_catalogue/catalogue_tc/catalogue_detail.htm?csnumber $=43170$ (Access date: 4 May, 2015).

[4] Katsicas, S. K., (2009). "35" Computer and Information Security Handbook Morgan Kaufmann Publications Elsevier Inc p. 605. ISBN 978-0-12-374354-1.

[5] ISACA (2009). ISACA The Risk it Framework, http://www.isaca.org/Knowledge-Center/Research/Docu ments/RiskIT-FW-18. Nov 09-Research.pdf, 43170 (Access date: 21 June, 2015).

[6] Kohout, K., (2012). Master's thesis, available at http://ww w.isaca.org (Access date: 11 June, 2015).

[7] Gordon, A. L.S., Belik, I., Rahimi, S., (2010). "A Hybrid Expert System for IT Security Risk Assessment". International Conference on Parallel and Distributed Processing Techniques and Applications (PDPTA'10), Las Vegas, 2010. 